\title{
Dispersion Coefficient Prediction Using Empirical Models and ANNs
}

\author{
Vassilis Z. Antonopoulos ${ }^{1} \cdot$ Pantazis E. Georgiou $^{1}$ • \\ Zissis V. Antonopoulos ${ }^{1}$
}

Received: 5 November 2014 / Accepted: 21 March 2015 / Published online: 7 May 2015

(C) Springer International Publishing Switzerland 2015

\begin{abstract}
The concentration of a conservative pollutant is changed along a river, as a result of transport processes. The dispersion coefficient is the most important parameter of mass transport in rivers. In this paper, the dispersion coefficient was estimated in a section of Axios River, with the analytical procedure of Fischer method, under different hydrological and hydrodynamic conditions. An empirical equation and a model of artificial neural networks (ANNs) for dispersion coefficient were proposed, based on the data estimated with analytical Fischer method. The dispersion coefficients predicted by the proposed models and other empirical equations reported in earlier studies were compared to the coefficients obtained in the present study. The most accurate equations for dispersion coefficient were used to predict the concentration of conservative toxic pollutants released instantaneously in Axios River upstream of the border of Greece-Former Yugoslav Republic of Macedonia (FYROM).
\end{abstract}

Keywords Dispersion coefficient $\cdot$ Empirical equations $\cdot$ Artificial neural networks $\cdot$ Mass transport $\cdot$ Pollution $\cdot$ Axios river

\section{Introduction}

Quantitative and qualitative changes in water resources systems have increasingly captured the attention of the international community over the last decades. The European Community, with the Water Framework Directive (WFD) 2000/60 (EU 2000), raised the status of water quantity and quality in surface and subsurface water resources systems. According to the WFD, the sustainability, protection and improvement of the ecological status in all the surface and subsurface water resources systems are necessary. In the case of international rivers and

Vassilis Z. Antonopoulos

vasanton@agro.auth.gr

1 Department of Hydraulics, Soil Science and Agricultural Engineering, School of Agriculture, Aristotle University of Thessaloniki, 54124 Thessaloniki, Greece 
lakes, the WFD encourages member states to cooperate with non-member states for the water resources management at the river basin scale.

Hazardous contaminants and effluents discharged into the river are under mixing as they are transported downstream by the flowing water. Non-conservative solutes are simultaneously under the effects of biological and chemical transformations. The concentration of a solute along the river depends on the processes of convection-dispersion and transformations.

The intensity of the mixing in rivers is evaluated by the longitudinal dispersion coefficient (D). The longitudinal dispersion in the river is the result of many hydrodynamic parameters including the cross-channel geometry and the variation of the velocity in the cross-section (Fischer et al. 1979; Seo and Cheong 1998). A range of variables affect the longitudinal dispersion coefficient in the rivers. The most important variables are channel width, flow depth, mean velocity, shear velocity, bed slope, bed roughness, horizontal stream curvature and bed shape factor (Seo and Cheong 1998).

Several techniques have been derived for predicting dispersion coefficient. The most common approaches are the method of moments, Fischer's integration procedure over cross section distribution of velocity, empirical equations and through calibration of mass transport models. Details of these are common place in the literature (appearing, for example, in Fischer et al. 1979; Rutherford 1994; Chapra 1997; Singh and Beck 2003; Valiskova et al. 2014). The values obtained for the longitudinal dispersion coefficient D using different methods have often varied widely and the reason is that they are based on different assumptions in the flow conditions.

Artificial neural networks (ANNs) are being used increasingly to predict and forecast water resources variables. ANNs have been successfully used in hydrological processes, water resources management, water quality prediction, and reservoir operation (Maier and Dandy 1996; ASCE 2000; Diamantopoulou et al. 2006, 2007; Kourakos and Mantoglou 2009; Trichakis et al. 2009; Antonopoulos et al. 2012). In the last decade, they were used to estimate D (Kashefipour and Falconer 2002; Rowinski et al. 2005; Sahay 2013), where the measured data are often noisy, with errors and do not represent properly the underlying population (Piotrowski et al. 2012).

Most dispersion coefficient models, either as empirical equations or with the ANN techniques, derived using data sets from many rivers over the world published by Fischer (1967), Seo and Cheong (1998), Kashefipour and Falconer (2002), Tayfur and Singh (2005), Piotrowski et al. (2012) and Etemad-Shahidi and Taghipour (2012). However, use of these models to estimate the dispersion coefficient, usually results in significant errors overestimating or underestimating the coefficient. Equations with data sets from specific rivers are rarely presented, because the data sets mining is very difficult and the channel characteristics change continuously due to high and low discharge in the river.

The main purpose of this study is to develop an artificial neural network to predict the longitudinal dispersion coefficient (D) in Axios River, a transboundary river between Greece and FYROM. Data for D in Axios River was obtained using the analytical procedure of integral expression presented by Fischer $(1967,1968)$ and the data from the measurements of discharge at the hydrometric station of Axioupolis. A simple empirical equation has been also developed for the D and ANN models derived to estimate it. This equation and ANN models have been compared with other existing empirical equations published in the recent literature as in Seo and Cheong (1998). The D estimating values by the different equations and models for Axios river were used in the advection-diffusion equation to predict the concentration distribution along the river. 


\section{Materials and Methods}

\subsection{Theory of Dispersion and Empirical Equations}

The classic approach of one-dimensional mass transport in rivers is based on the advectiondispersion equation, which in a more general form including variable channel characteristics and solute transformation described as (Fischer et al. 1979; Chapra 1997):

$$
\frac{\partial \mathrm{C}}{\partial \mathrm{t}}=\frac{1}{\mathrm{~A}} \frac{\partial}{\partial \mathrm{x}}\left(\mathrm{AD} \frac{\partial \mathrm{C}}{\partial \mathrm{x}}\right)-\frac{1}{\mathrm{~A}} \frac{\partial(\mathrm{AUC})}{\partial x}+\mathrm{R}_{\mathrm{i}}+\mathrm{S}_{\mathrm{i}}
$$

where $\mathrm{C}$ is the mean cross-sectional concentration $\left(\mathrm{ML}^{-3}\right), \mathrm{A}$ is the cross-sectional area $\left(\mathrm{L}^{2}\right), \mathrm{D}$ is the longitudinal dispersion coefficient $\left(\mathrm{L}^{2} \mathrm{~T}^{-1}\right), \mathrm{U}$ is the mean cross-sectional velocity $\left(\mathrm{LT}^{-1}\right), \mathrm{x}$ is the distance $(\mathrm{L}), \mathrm{t}$ is the time $(\mathrm{T})$ and $\mathrm{S}_{\mathrm{i}}$ is a term of inflow/outflow $\left(\mathrm{M} \mathrm{L}^{-3}\right.$ $\left.\mathrm{T}^{-1}\right)$. The term $\mathrm{R}_{\mathrm{i}}(=\mathrm{dC} / \mathrm{dt})$ describes the rate of concentration change due to transformations of solute $\left(\mathrm{M} \mathrm{L}^{-3} \mathrm{~T}^{-1}\right)$.

The solution of Eq. (1) for the conditions of a conservative solute $\left(\mathrm{R}_{\mathrm{i}}=0\right)$, steady-state and uniform flow (U and A constant), without inflow/outflow $\left(\mathrm{S}_{\mathrm{i}}=0\right)$ and the upstream boundary condition of instantaneous point source is given by (Chapra 1997):

$$
\begin{gathered}
C=\frac{M}{A \sqrt{4 \pi \mathrm{Dt}}} \exp \left(-\frac{(\mathrm{x}-\mathrm{Ut})^{2}}{4 \mathrm{Dt}}\right) \\
\mathrm{C}_{\max }=\frac{\mathrm{M}}{\mathrm{A} \sqrt{4 \pi \mathrm{Dt}}}
\end{gathered}
$$

where $\mathrm{M}$ is the mass of solute released instantaneously in the river and $\mathrm{C}_{\max }$ is the maximum concentration of solute at time $\mathrm{t}\left(\mathrm{ML}^{-3}\right)$.

Fischer (1967) introduced the following integral equation to estimate the longitudinal dispersion coefficient, which is based on the integration of mass conservation equation over the depth with boundary conditions of no mass flux across the bed and water surface:

$$
D=-\frac{1}{A} \int_{0}^{w} q^{\prime}(y)\left\{\int_{0}^{y} \frac{1}{E_{y} d(y)}\left[\int_{0}^{y} q^{\prime}(y) d y\right] d y\right\} d y
$$

where $w$ is the channel width (L), d(y) is the local flow depth (L), q'(y) is the depth integrated velocity at point $y$ as

$$
\mathrm{q}^{\prime}(\mathrm{y})=\int_{0}^{\mathrm{d}(\mathrm{y})} \mathrm{u}^{\prime}(\mathrm{y}, \mathrm{z}) \mathrm{dz}
$$

$\mathrm{u}^{\prime}(\mathrm{y}, \mathrm{z})$ is the deviation of the velocity $\left(\mathrm{LT}^{-1}\right)$ from the cross-sectional mean velocity (e.g., $u^{\prime}(y, z)=u(y, z)-U$, where $u(y, z)$ is the velocity at each point of cross-section and $U$ is the crosssectional average velocity $\left.\left(\mathrm{LT}^{-1}\right)\right), \mathrm{E}_{\mathrm{y}}\left(\mathrm{E}_{\mathrm{y}}=0.23 \mathrm{~d} \mathrm{u}\right)$ is the transverse turbulent diffusion coefficient, $\mathrm{z}$ is the vertical distance, $\mathrm{y}$ is the transverse distance, $\mathrm{u} *\left(\mathrm{u} *=\sqrt{\mathrm{gRS}_{\mathrm{f}}}\right)$ is the bed shear velocity with $g$ the gravity acceleration $\left(\mathrm{LT}^{-2}\right), \mathrm{R}$ is the hydraulic radius $(\mathrm{L})$ and $\mathrm{S}_{\mathrm{f}}$ is the gradient of energy line (-). 
The dispersion coefficient could be estimated using Eq. (4) with detailed geometric and velocity distribution data of cross-section of river channel. Equation (4) was derived by Fischer (1967, 1968) under the assumptions that water flow is uniform and that the transverse variations of the downstream velocity are the primary producers of dispersion in a natural stream. The difficulties to use Eq. (4) and the unavailability of detailed transverse velocity profile led the research to investigate simplified non-integral equations based on simply measured variables of cross-section and water flow (Mc Quivey and Keefer 1974; Fischer et al. 1979; Seo and Cheong 1998; Papadimitrakis and Orphanos 2004).

Fischer (1975), to simplify the procedure of dispersion coefficient, proposed the nonintegral form of Eq. (4) as:

$$
\mathrm{D}=\frac{0.011 \mathrm{U}^{2} \mathrm{w}^{2}}{\mathrm{Hu} *}
$$

where $\mathrm{H}$ is the cross-sectional average flow depth (L).

Equation (5) was widely used for many years. It became unpopular in the last year, because it gives significant deviation between predicted and measured values of $\mathrm{D}$. This deviation is usually the result of shear stress and the difficulty in representing the velocity in cross sections of the stream (Sahay 2013). Since 1975, several empirical equations have been presented as a function of the hydraulic and geometric parameters, using existing measured data in rivers and by applying dimensional or regression analysis. A general equation for the dispersion coefficient suggested by many researchers has the following form:

$$
\mathrm{D}=\alpha(\mathrm{Hu} *)\left(\frac{\mathrm{U}}{\mathrm{u} *}\right)^{\mathrm{b}}\left(\frac{\mathrm{W}}{\mathrm{H}}\right)^{\mathrm{c}}
$$

where $\alpha, \mathrm{b}$ and $\mathrm{c}$ are constants.

The constants of Eq. (6) were estimated using dimensional and regression analysis from data sets from many rivers over the world published by Fischer (1967), Seo and Cheong (1998), Rowinski et al. (2005), Tayfur and Singh (2005), Antonopoulos and Antonopoulos (2009), Piotrowski et al. (2012), Etemad-Shahidi and Taghipour (2012) and Sahin (2014). The data sets which were used from the previous cited articles were enhanced over the years with new data sets. In Table 1, the values of constants of Eq. (6) suggested by some researchers are presented. Many other expressions have been presented as modifications of Eq. (6) or similar empirical equations (Mc Quivey and Keefer 1974; Deng et al. 2001; Kashefipour and Falconer 2002).

Table 1 Constants in the different expressions of D (in $\mathrm{m}^{2} / \mathrm{s}$ ) in Eq. (6)

\begin{tabular}{llll}
\hline Expression & $\mathrm{a}$ & $\mathrm{b}$ & $\mathrm{c}$ \\
\hline Fischer (1975) & 0.011 & 2 & 2 \\
Liu (1977) & 0.18 & 0.5 & 2 \\
Seo and Cheong (1998) & 5.915 & 1.428 & 0.62 \\
Koussis and Rodriguez-Mirasol (1998) & 0.6 & 0.0 & 2 \\
Sahay and Dutta (2009) & 2.0 & 1.25 & 0.96 \\
Etemad-Shahidi and Taghipour (2012), if w/H $\leq 30.6$ and if $\mathrm{w} / \mathrm{H}>30.6$ & 15.49 & 0.11 & 0.78 \\
& 14.12 & 0.85 & 0.61 \\
\hline
\end{tabular}




\subsection{Artificial Neural Networks (ANNs)}

ANNs are flexible modelling tools with the capability of learning the mathematical mapping between input and output variables of non-linear systems. They are capable of providing a neurocomputing approach to solving complex problems. In the last decade, ANNs have been employed in the solution of various water resources problems, such as rainfall-runoff modelling (Loukas et al. 2002; Sentil-Kumar et al. 2005), groundwater problems (Mantoglou 2003; Garcia and Shigidi 2006) and water quality problems (Diamantopoulou et al. 2007; Akratos et al. 2008; Dogan et al. 2009; Pai and Lee 2010). ANNs have also been applied to complete missing data in hydrology, meteorology and water quality modelling. As example, Diamantopoulou et al. (2007) applied the cascade correlation ANN models to estimate missing monthly values of water quality parameters in rivers.

The ANN architecture is defined by the number of neurons and the way in which the neurons are interconnected. The network is fed with a set of input-output pairs and trained to reproduce the output. The structure of each ANN is represented as $(\mathrm{i}, \mathrm{j}, \mathrm{k})$, where $\mathrm{i}$ express the number of nodes in the input layer, $\mathrm{j}$ the nodes in hidden layer, and $\mathrm{k}$ the nodes in the output layer. The neurons are connected to each other by links, known as synapses. A hidden neuron layer adds up a weight value, received from each input neuron, and then passes the results through a nonlinear function. Figure 1 presents the structure of this ANN (4-5-1).

Among various ANNs is the three-layer feed-forward network (FFNN). In feed-forward ANNs, the input signal propagates through the network in a forward direction, from layer of inputs to the hidden layer and then to output neuron. Quickprop algorithm was used for training in this study (Fahlman 1988; Antonopoulos et al. 2012). This algorithm is a variant of the classic back propagation algorithm that aims at increasing convergence rate. It uses two training parameters and two testing parameters: the training rate $n$, the initial addition to the sigmoid function (sigmoid prime offset), the maximum growth factor (max factor) and the maximum range of weights (weight range). With the Quickprop algorithm, one can achieve a faster conversion of the weights than using the classic back-propagation algorithm.

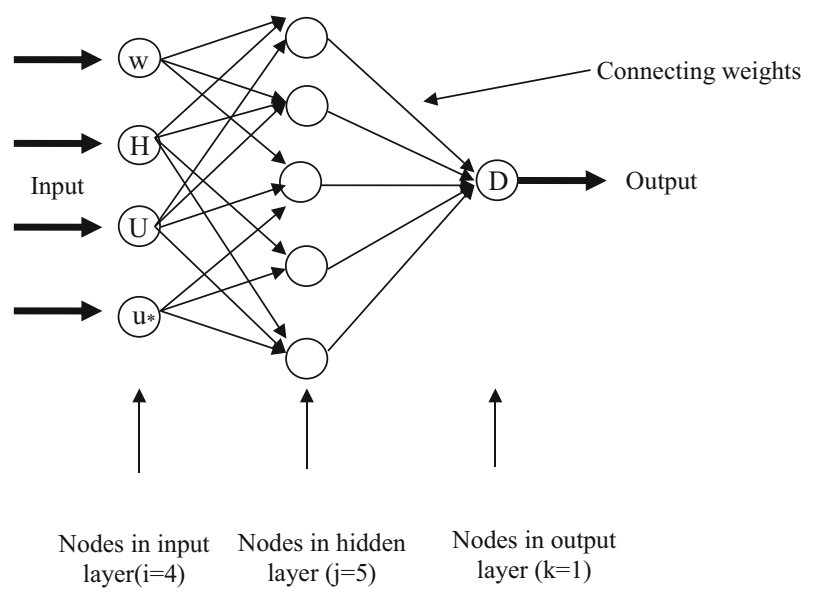

Fig. 1 Example of ANN structure 
Using the Quickprop algorithm (Fahlman 1988), the weight variation is calculated by means of the following equation:

$$
\Delta(\mathrm{t}+1) \cdot \mathrm{w}_{\mathrm{ij}}=\frac{\mathrm{S}(\mathrm{t}+1)}{\mathrm{S}(\mathrm{t})-\mathrm{S}(\mathrm{t}+1)} \cdot \Delta(\mathrm{t}) \cdot \mathrm{w}_{\mathrm{ij}}
$$

where $\mathrm{w}_{\mathrm{ij}}$ is the weight between $i$ and $j$ neurons, $\Delta(\mathrm{t}+1)$ is the weight variation, $\mathrm{S}(\mathrm{t}+1)$ is the partial derivative of the error function of the weight $\mathrm{w}_{\mathrm{ij}}$, and $\mathrm{S}(\mathrm{t})$ is the previous partial derivative.

To avoid convergence problems and extremely small weighting factors, when large values of input and output are used, it is prudent to standardize all external input and output values before passing into the ANN network. There are no fixed rules for the standardization approach (Tayfur and Singh 2005). In this study, the following method was used:

$$
\mathrm{z}_{\mathrm{i}}=\frac{\mathrm{x}_{\mathrm{i}}}{\mathrm{x}_{\max }+1}
$$

where $\mathrm{z}_{\mathrm{i}}$ is the standardized value, $\mathrm{x}_{\mathrm{i}}$ is the real input or output value and $\mathrm{x}_{\max }$ is the maximum input or output value of all values.

In the present study, the value of D is estimated by means of ANN with the independent variables of channel width $(\mathrm{w})$, the mean depth of flow $(\mathrm{H})$, the cross-sectional averaged velocity $(\mathrm{U})$, and the shear velocity $\left(\mathrm{u}_{*}\right)$.

\subsection{Modelling Performance Criteria}

The performance of the development models (empirical equations and ANN models) was evaluated again the estimated values of D using the integral equation (Eq. (4)) of Fischer (1968) by using error measures such as the discrepancy ratio (DR), the mean absolute error (ME) and the root mean square error (RMSE). These statistical parameters are defined as:

Discrepancy ratio (DR) (Seo and Cheong 1998):

$$
\mathrm{DR}=\log _{(10)} \frac{\mathrm{D}_{\mathrm{pr}}}{\mathrm{D}_{\mathrm{me}}}
$$

where $D_{p r}$ and $D_{m e}$ are the predicted and measured dispersion coefficients, respectively. If DR is equal to zero, the measured and predicted values are identical. There is either an overestimation if the DR $>0.0$, or an under-estimation if DR $<0.0$. Accuracy is defined as the percentage of DR values that fall between -0.3 and +0.3 (Seo and Cheong 1998; Kashefipour and Falconer 2002).

Mean absolute error (ME) and the root mean square error (RMSE) are defined as:

$$
\begin{aligned}
\mathrm{ME} & =\frac{1}{\mathrm{n}} \sum_{\mathrm{i}=1}^{\mathrm{n}}\left|\mathrm{DR}_{\mathrm{i}}\right|, \\
\mathrm{RMSE} & =\frac{1}{\mathrm{n}} \sqrt{\sum_{\mathrm{i}=1}^{\mathrm{n}}\left(\mathrm{DR}_{\mathrm{i}}\right)^{2}}
\end{aligned}
$$


where $\mathrm{n}$ is the total number of data. For accurate model performance, the values of ME and RMSE should be as close as possible to zero.

\subsection{Study Area and Data Sets}

Axios River is a transboundary river of Greece and FYROM in South Eastern Europe. Its length is about $376 \mathrm{~km}$, approximately $76 \mathrm{~km}$ of which are in Greek territory. The area of its watershed is approximately $22,450,2,300 \mathrm{~km}^{2}(10 \%)$ of which are in Greece (Fig. 2). The delta of Axios River is one of the most important Greek protection area and one of the 10 wetlands of international importance according to the Ramsar convention. The river supplies irrigation water for about 30,000 ha in Thessaloniki plain of Greece.

The average discharge for the period of 1980-94 was $101.1 \mathrm{~m}^{3} / \mathrm{s}$, with maximum discharge 443.6 and minimum $4.5 \mathrm{~m}^{3} / \mathrm{s}$ (Diamantopoulou et al. 2007). The municipal, industrial and agricultural activities in the basin of Axios river upstream of the Greece-FYROM border is an important source of pollution to the downstream part of the river, the delta and the Aegean Sea. There were also some emergency times when accidents with industrial and dangerous toxic products were spilled in to the river and were associated with water quality degradation along the stream.

A few kilometers downstream of the Greece-FYROM borders, at Axioupolis, a hydrometric (current meter method) and water quality monitoring station have been established (Fig. 2). This station has been included in the European Community's water quality monitoring program (EC 1994) since 1982.

Discharge measurements for the time period of May 2004 to November 2010 were used to obtain the necessary data. In each measurement, the cross-section was divided in 10 to 14 sections, in each one of them the mean vertical velocity and the geometric data (depth and width) were measured. Using these data of velocity distribution over the cross-section, the dispersion coefficient was estimated throughout using Eq. (4), as it was described by Fischer

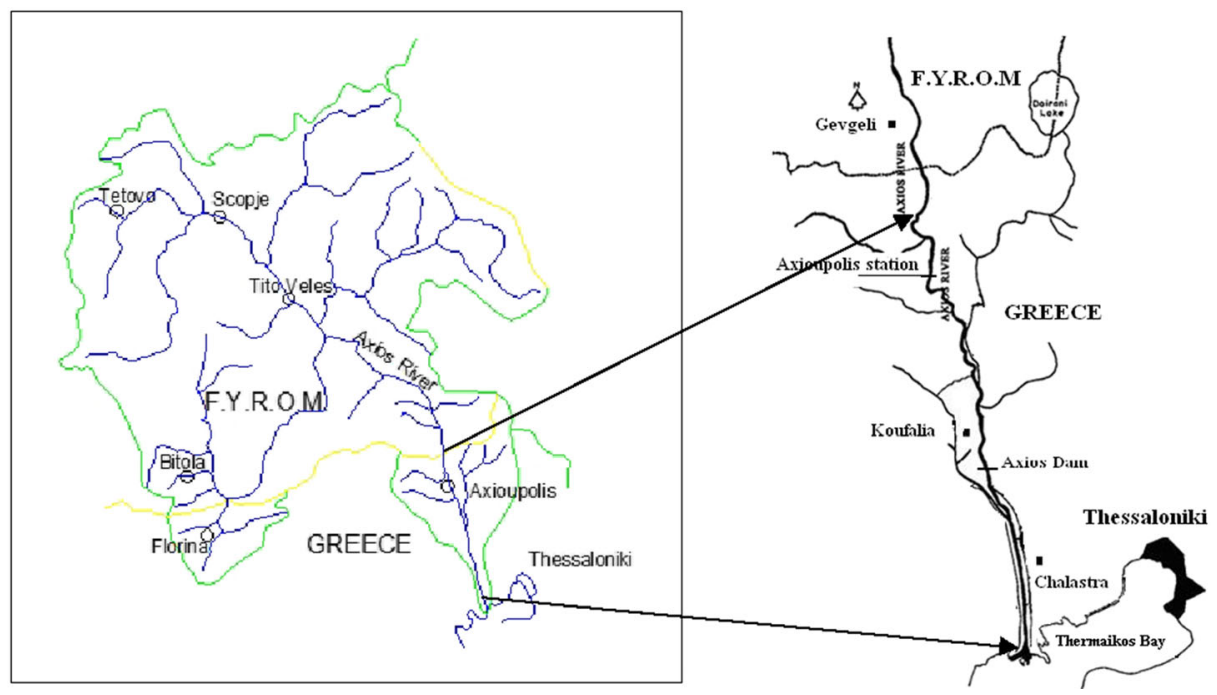

Fig. 2 Axios river watershed, the site of hydrometric and water quality monitoring station, and the hydrographic network in the Greek part of the river 
(1968). The values of $\mathrm{w}, H, U$ and $\mathrm{u}_{*}$ were used to estimate the constants of Eq. (6) for Axios River (proposed empirical equation) and to develop the most appropriate ANN models (ANNAxios) for D.

\section{Results and Discussion}

\subsection{Dispersion Coefficient from Analytical and Empirical Equation}

The data set of 32 measurements at the Axioupolis station were used to estimate D with the "analytical procedure" described by Fischer (1967) and Fischer et al. (1979). The phrase "analytical procedure" is used in the article to describe the estimated values of D with Eq. (4). In Table 2, the average, maximum and minimum values of depth, width, discharge, velocity, shear velocity and the estimated values of dispersion coefficient from available pairs of data are presented. For the river's water discharge ranging from 39.07 to $471.76 \mathrm{~m}^{3} / \mathrm{s}$, the dispersion coefficient is ranging from 24.56 to $763.20 \mathrm{~m}^{2} / \mathrm{s}$.

Using multiple regression analysis between the depended variable of $\mathrm{D}$ and the independent variables of $\mathrm{w}, \mathrm{H}, \mathrm{U}$ and $\mathrm{u} *$ the following equation was derived:

$$
\mathrm{D}_{\text {AXIOS }}=0.000017625(\mathrm{Hu} *)\left(\frac{\mathrm{U}}{\mathrm{u} *}\right)^{0.806657}\left(\frac{\mathrm{W}}{\mathrm{H}}\right)^{3.93023}
$$

The estimated values of $\mathrm{D}_{\text {AXIOS }}$ using the proposed Eq. (11) were plotted against the values obtained by analytical Fischer procedure (D $\mathrm{D}_{\text {ANALYTICAL }}$, Eq. (4)) and are presented in Fig. 3a.

The empirical dispersion coefficient equations proposed by Fischer $\left(\mathrm{D}_{\mathrm{FISCHER}}\right.$, Eq. (5)), Liu (D $\mathrm{D}_{\text {LiU }}$, Eq. (6)), and Seo and Cheong ( $\mathrm{D}_{\text {SEOCHEONG }}$, Eq. (6)), were then used to predict $\mathrm{D}$ for the pairs of data. The comparison of predicted values of dispersion coefficient using these equations with the analytical procedure estimated values is presented in Fig 3b, c and d.

In Table 3, the error measures of various empirical equations reported in earlier studies ( $\mathrm{D}_{\text {FISCHER }}, \mathrm{D}_{\text {SEOCheONG }}$ and $\mathrm{D}_{\text {LIU }}$ ) and the proposed empirical equation for Axios River ( $\mathrm{D}_{\text {AXIOS }}$ ) are presented. The accuracy of each model may be ranked by the number of DR values between -0.3 and 0.3 relatively to total number of data values (Seo and Cheong 1998; Kashefipour and Falconer 2002). From Table 3, the accuracy of the Axios empirical equation proposed here is $56 \%$ and that of the Liu equation is $47 \%$, which are the highest among the four compared equations. The Fischer and Seo and

Table 2 Statistical parameters of available data sets of cross-section and hydraulic variable of Axios River at the Axioupolis station

\begin{tabular}{llllllll}
\hline & $\begin{array}{l}\text { Depth } \mathrm{H} \\
(\mathrm{m})\end{array}$ & $\begin{array}{l}\text { Width w } \\
(\mathrm{m})\end{array}$ & $\begin{array}{l}\text { Area A } \\
\left(\mathrm{m}^{2}\right)\end{array}$ & $\begin{array}{l}\text { Discharge Q } \\
\left(\mathrm{m}^{3} / \mathrm{s}\right)\end{array}$ & $\begin{array}{l}\text { Velocity } \mathrm{U} \\
(\mathrm{m} / \mathrm{s})\end{array}$ & $\begin{array}{l}\mathrm{u}_{*}=(\mathrm{gdS})^{1 / 2} \\
(\mathrm{~m} / \mathrm{s})\end{array}$ & $\begin{array}{l}\mathrm{D}_{\text {ANALYTICAL }} \\
\left(\mathrm{m}^{2} / \mathrm{s}\right)\end{array}$ \\
\hline Average & 1.62 & 100.34 & 164.27 & 153.57 & 0.84 & 0.09 & 222.50 \\
Max & 2.74 & 113.00 & 306.56 & 471.76 & 1.61 & 0.12 & 763.20 \\
Min & 0.82 & 80.00 & 74.20 & 39.07 & 0.38 & 0.07 & 24.56 \\
Sdev & 0.51 & 7.08 & 59.94 & 110.86 & 0.32 & 0.01 & 207.74 \\
\hline
\end{tabular}



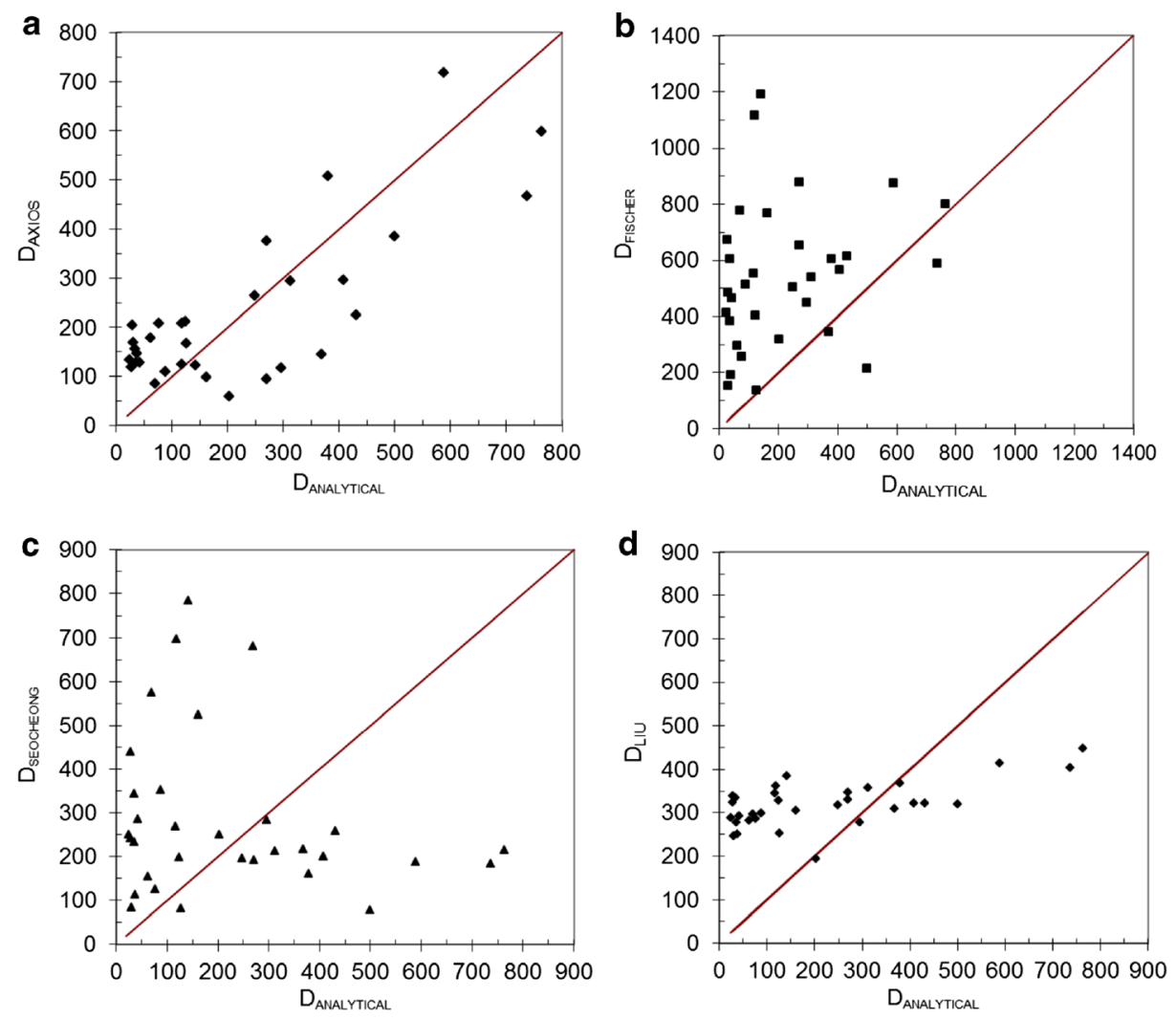

Fig. 3 Comparison of predicted dispersion coefficient with data sets values using equation of: (a) Axios

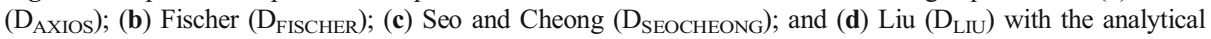
estimated values

Cheong equations accuracies are lower at 34 and $31 \%$. This ranking of those four equations (Axios, Liu, Fischer, and Seo and Cheong) is also verified with the values of root mean square error (RMSE) and mean error (ME) which show different range among the four equations, with better results for Axios equation, followed by Liu and Seo and Cheong, and a poor prediction from Fischer equation.

Table 3 Comparison of the performance of various models

\begin{tabular}{llllll}
\hline & \multicolumn{2}{l}{ DR } & & ME & RMSE \\
\cline { 2 - 5 } & $<-0.3$ & $-0.3<\mathrm{DR}<0.3$ & $>0.3$ & & \\
\hline Fischer (1975) & $3 \%(1)$ & $34 \%(11)$ & $62 \%(20)$ & 0.57 & 0.125 \\
Liu(1977) & $0 \%(0)$ & $47 \%(15)$ & $53 \%(17)$ & 0.44 & 0.099 \\
Seo and Cheong (1998) & $19 \%(6)$ & $31 \%(10)$ & $50 \%(16)$ & 0.50 & 0.105 \\
AXIOS model & $13 \%(4)$ & $56 \%(18)$ & $31 \%(10)$ & 0.32 & 0.071 \\
ANN (4-12-1) & $13 \%(4)$ & $56 \%(18)$ & $31 \%(10)$ & 0.29 & 0.063 \\
ANN (3-12-1) & $9 \%(3)$ & $53 \%(17)$ & $38 \%(12)$ & 0.33 & 0.073 \\
\hline
\end{tabular}


Figure 3 and the values of Table 3 show that the empirical Axios equation overestimates the low values of $\mathrm{D}$ and underestimates the high values. Fischer equation mainly overestimates the values of $\mathrm{D}$, while the Seo and Cheong model overestimates the low values and underestimates the high values. Liu equation estimates $\mathrm{D}$ in a narrow range of values.

The study of Etemad-Shahidi and Taghipour (2012) on the performance of a model tree and the comparison with other empirical equations reported in earlier studies by using 149 field data that were measured in difference rivers, showed that the accuracy of model tree was $63 \%$, followed by Liu (1977) model with $51 \%$ and then by Seo and Cheong (1998), Kashefipour and Falconer (2002), Sahay and Dutta (2009) equations with accuracy between 45 and $49 \%$.

\subsection{ANN Models}

The data sets of the following variables $\mathrm{H}, \mathrm{w}, U$ and $\mathrm{u}_{*}$ were used as input and the values of $\mathrm{D}_{\text {AnAlytical }}$ as output target variable. Two cases were examined. In the 1 st case, the 4 variables $\left(\mathrm{H}, \mathrm{w}, \mathrm{U}, \mathrm{u}_{*}\right)$, before the training and testing were standardized by Eq. (8), and were used as input variables. In the $2 \mathrm{nd}$ case, the product of $\mathrm{Hu}_{*}$, and the non-dimensional variables $\mathrm{w} / \mathrm{H}$ and $\mathrm{U} / \mathrm{u}_{*}$ were used, after standardization, as input variables. The target output variable $\mathrm{D}$ was also standardized before the training and testing.

It is known that ANN models give accurate predictions when there are enough data sets for training and testing procedures. In the case of dispersion coefficient it is very difficult to obtain data sets in such large number. The ANN has been applied to predict dispersion coefficient in many cases using a number of data sets ranging from 50 to 100. As an example, Tayfur and Singh (2005) used 65 datasets, Sahin (2014) used 45 dataset, etc. In this paper, twenty five data sets from the total available data (32) were used for training of the ANN models and the remaining sets (7) were employed for testing the model.

In choosing the data sets for testing, special attention was paid to have representative sets for each class of dispersion coefficient values. For the number of neurons in the hidden layer, a trial and error procedure was used. The most appropriate model is the 412-1, which means that the model was constructed with 4 input variables, 12 hidden layers and 1 output layer. In the 2 nd case, the notation of the most appropriate model is ANN 3-12-1.

Figure 4 shows the comparison of dispersion coefficient predicted by the artificial neural networks model of structure 3-12-1 versus the $\mathrm{D}_{\text {ANALYTICAL }}$ values, while Fig. 5 shows the comparison for the ANN model of 4-12-1 structure. Figure 4a (and 5a) presents the comparison when 25 datasets were used for training and 7 data for testing and $4 \mathrm{~b}$ (and 5b) the comparison when all the data sets were used for training and testing.

The differences between the results of the ANNs either with 4 variables in the input layer, or with 3 are very small. The RSME for those two ANN [(3-12-1), (4-12-1)] models are 106.2 and $98.09 \mathrm{~m}^{2} / \mathrm{s}$ and the correlation coefficient (r) are 0.816 and 0.888 , respectively, when 25 data sets were used for training. Those criteria are 126.85 and $117.26 \mathrm{~m}^{2} / \mathrm{s}$ and 0.785 and 0.804 , respectively, when all the data sets were used for training and testing.

The error measures of ANN models in comparison the others examined empirical equations ( $\mathrm{D}_{\text {AXIOS }}, \mathrm{D}_{\text {FISCher }}, \mathrm{D}_{\mathrm{SEOCheONG}}$ and $\mathrm{D}_{\text {LIU }}$ ) are presented in Table 3. From Table 3, the accuracy of ANN models is $56 \%$, which is the highest of examined models. It is indicated and by the values of other statistical criteria (RMSE and ME). 

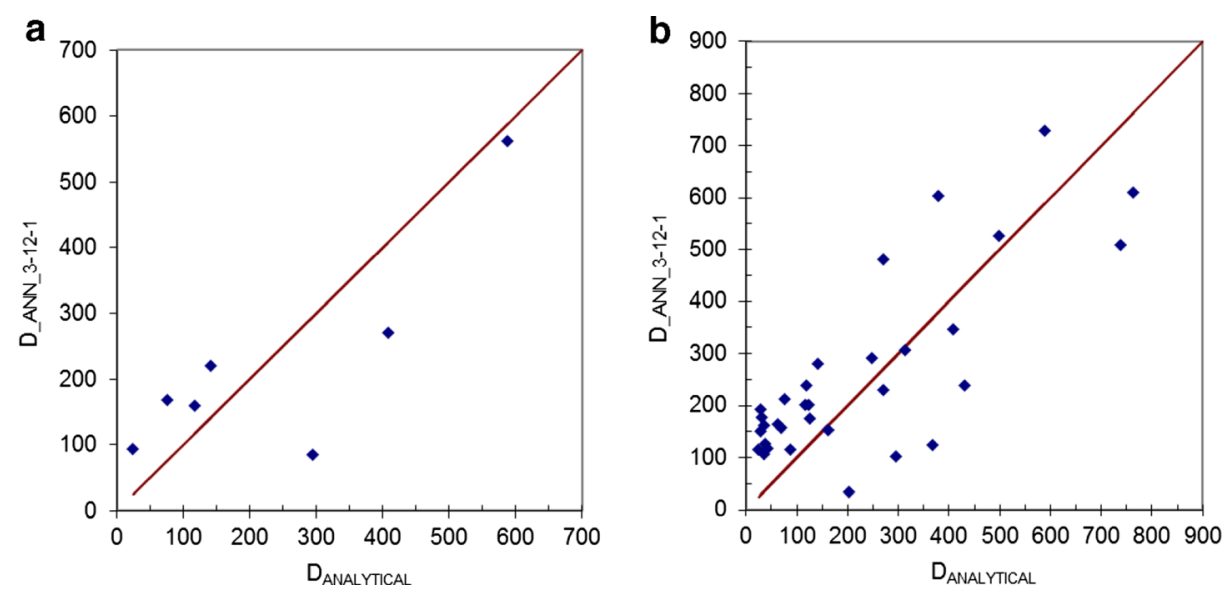

Fig. 4 Comparison of dispersion coefficient predicted by artificial neural networks versus analytical data using: (a) 25 data set for training and 7 data for testing; and (b) all the data for training and testing. The model input variables are the combined variables $\left(\mathrm{Hu}^{*}\right),(\mathrm{w} / \mathrm{H})$ and $\left(\mathrm{U} / \mathrm{u}^{*}\right)$

\subsection{Application of Models Using the Advection-Dispersion Equation in Axios River}

The comparison of predicted values of D using the proposed models ( $\mathrm{D}_{\mathrm{AXIOS}}$, Eq. (11)) and ANN model) and the examined empirical equations from the literature is one acceptable procedure. However, it is more practical to include all the above mentioned formulations in the advection-dispersion equation (i.e., Eq. (1)) to predict the distribution of concentration in the same way along the Axios River and then compare them among other or with measured data (if they are existing).

Equation (2) was used to predict concentration of a conservative solute along the Axios river from the Gevgelimotor way bridge (in FYROM) and for $20 \mathrm{~km}$ downstream. In this section of river, the flow condition was considered uniform and constant. The mean slope of
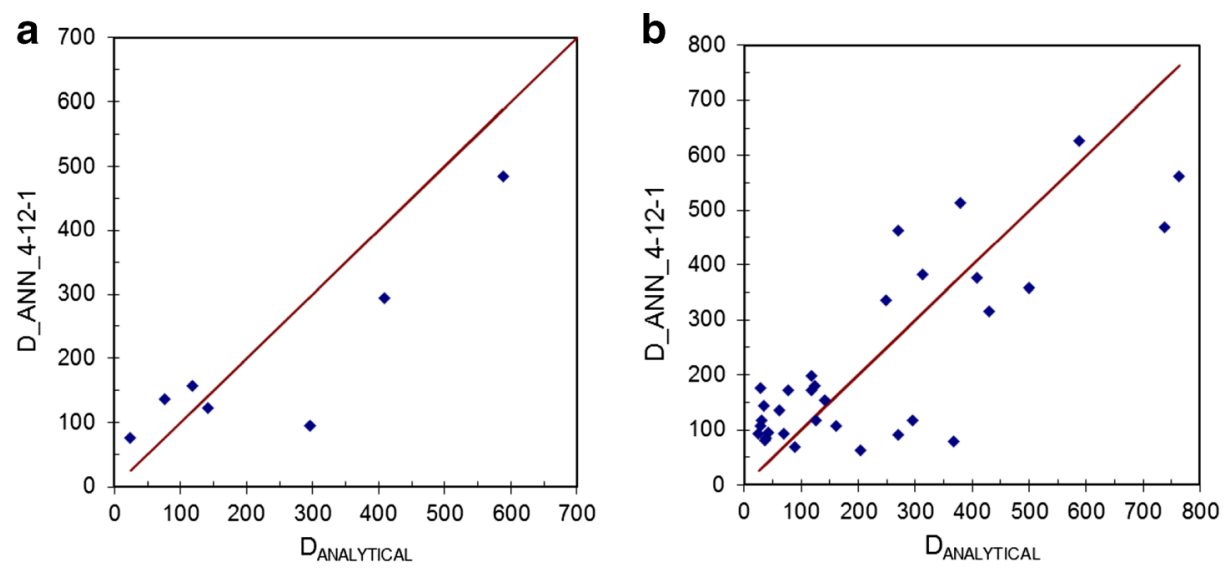

Fig. 5 Comparison of dispersion coefficient predicted by artificial neural networks versus analytical data using: (a) 25 data set for training and 7 data for testing; and (b) all the data for training and testing. The model input variables are $(\mathrm{H}),(\mathrm{w}),(\mathrm{U})$ and $\left(\mathrm{u}^{*}\right)$ 
Table 4 Data sets and dispersion coefficient by different existing and proposed model used in the mass transport equation

\begin{tabular}{llllllll}
\hline & $\mathrm{H}(\mathrm{m})$ & $\mathrm{w}(\mathrm{m})$ & $\mathrm{A}\left(\mathrm{m}^{2}\right)$ & $\mathrm{Q}\left(\mathrm{m}^{3} / \mathrm{s}\right)$ & $\mathrm{U}(\mathrm{m} / \mathrm{s})$ & $\mathrm{u}^{*}(\mathrm{~m} / \mathrm{s})$ & $\mathrm{D}_{\text {ANALYTICAL }}$ \\
$27 / 10 / 2010$ & 1.62 & 105 & 169.7 & 141.5 & 0.83 & 0.09 & 117.1 \\
$21 / 2 / 2006$ & 1.75 & 94 & 164.4 & 149.6 & 0.91 & 0.10 & 295.4 \\
& $\mathrm{D}_{\text {ANALYTICAL }}$ & $\mathrm{D}_{\text {AXIOS }}$ & $\mathrm{D}_{\text {FISCHER }}$ & $\mathrm{D}_{\text {SEOCHEONG }}$ & $\mathrm{D}_{\text {LIU }}$ & ANN $(3-12-1)$ & ANN $(4-12-1)$ \\
$27 / 10 / 2010$ & 117.1 & 207.4 & 532.6 & 265.2 & 343.9 & 201.48 & 197.93 \\
$21 / 2 / 2006$ & 295.4 & 116.3 & 450.1 & 283.7 & 277.5 & 103.03 & 117.68 \\
\hline
\end{tabular}

river bottom is estimated at 0.000614 and was assumed that it is identical to energy slope along the river. The river hydrodynamic parameters for concentration prediction are presented in Table 4. The values of dispersion coefficient corresponding to these conditions for the examined equations and the proposed models were also presented.

In Fig. 6, the concentration as a function of time at Axioupolis hydrometric station $(20 \mathrm{~km}$ downstream of solute spill) is presented. The data of the 1st case (27/10/2010) hydrodynamic conditions (Table 4) and the corresponding dispersion coefficient estimated by the proposed equation $\left(\mathrm{D}_{\mathrm{AXIOS}}\right)$ and the examined empirical equations were used. These concentrations were computed using the analytical solution (Eq. (2)) of the convection-dispersion equation. In Fig. 7, the corresponding curves of concentration distribution for the 2 nd case (21/2/2006)

Fig. 6 Concentration as function of time at Axioupolis station (20 km downstream of the spill) with different values of D estimated from the empirical and ANN models and data of 1 st case $(27 / 10 /$ 2010)
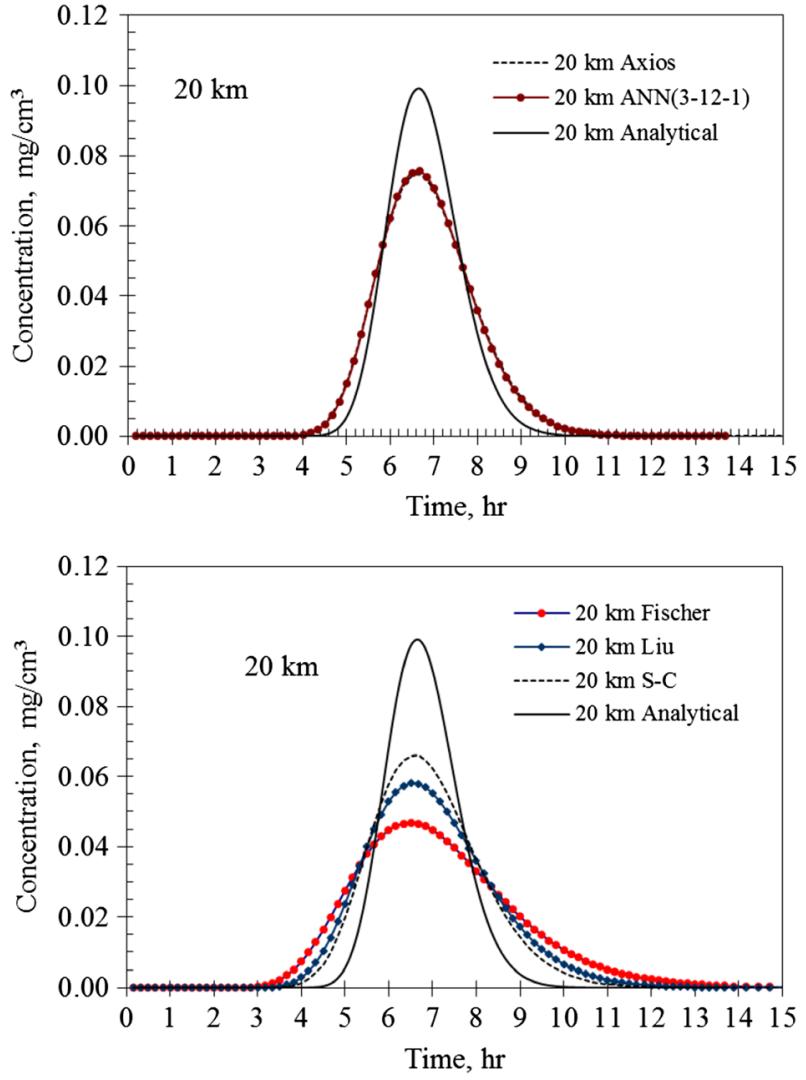
Fig. 7 Concentration as function of time at Axioupolis station (20 km downstream of the spill) with different values of D estimated from the empirical and ANN models and data of 2 nd case (21/2/ 2006)
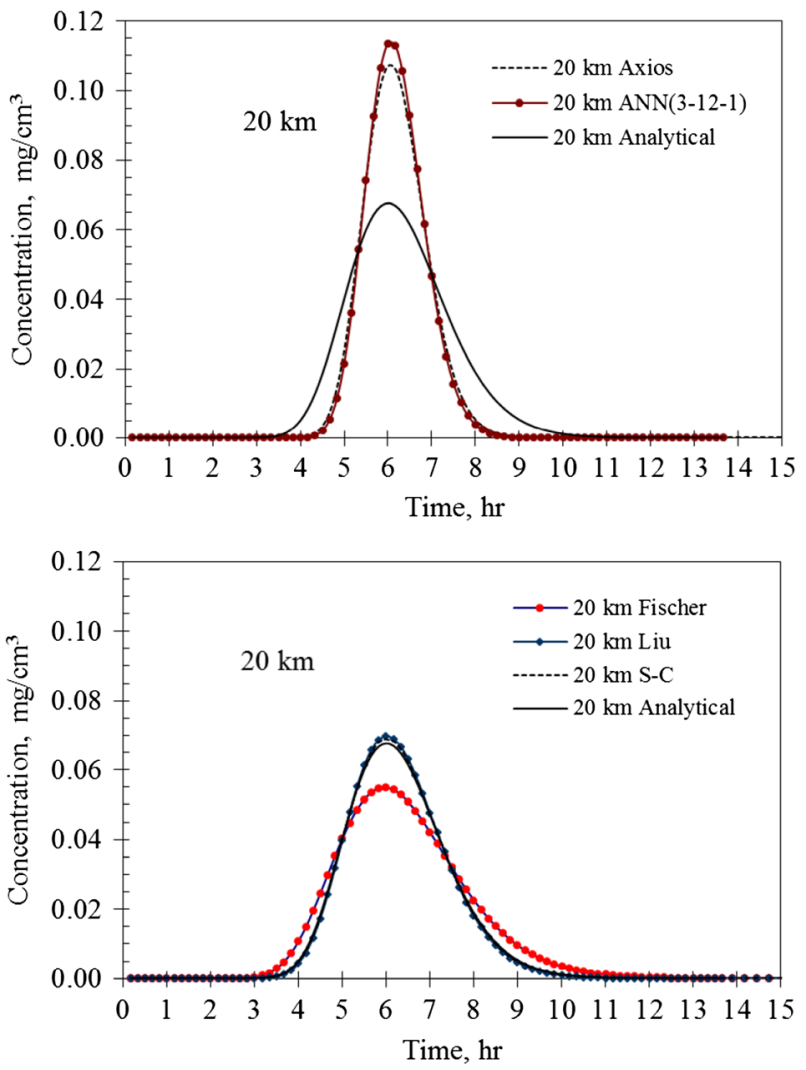

of hydrodynamic conditions in the river is presented. The differences in maximum concentration and the width of distribution are significant. Both proposed models $\left(\mathrm{D}_{\mathrm{AXIOS}}\right.$ model and $\left.\mathrm{D}_{\mathrm{ANN}}\right)$ give similar results because the estimated D is very close. Significant differences appear in the 1 st case (27/10/2010) of data set when the D was computed by Fisher, Liu and Seo and Cheong equations among them and from the $\mathrm{D}_{\text {ANALYTICAL }}$. With the data set of the 2 nd case (21/2/2006) Liu and Seo and Cheong equations give results close to $\mathrm{D}_{\text {ANALYTICAL. }}$

\section{Conclusions}

The dispersion coefficient is the most important parameter in the prediction of pollutant concentrations in natural streams using the one-dimensional convection-dispersion equation. It can be estimated using theoretical or empirical equations, based on flow variables and channel geometric characteristics.

Axios River is a significant transboundary river in South Eastern Europe. Data sets of channel geometry (depth, width, area) and flow (velocity distribution, mean shear velocity and discharge) obtained during the hydrometric measurements at Axioupolis station, about once a month for the period of 2004 to 2010. These data were used to estimate the dispersion coefficient by the Fischer (1968) analytical procedure, to estimate the constants of an empirical 
equation and to develop an artificial neural network for Axios river. All these models were compared with empirical equations from the literature, such as Fischer (1975), Liu (1977) and Seo and Cheong (1998) in therms of their performance in Axios River.

The comparison with the diagrams of $1: 1$ between values of $\mathrm{D}_{\text {ANALYTICAL }}$ and the estimated values by each model (available and proposed) led to the following conclusions:

- The accuracy of proposed empirical equation (Eq. (11)) was compared with the available equations of Fischer (1975), Liu (1977) and Seo and Cheong (1998) and was found better. The statistical criteria ME and RSME and the accuracy show the better results with Axios model, following by Liu and Seo and Cheong and poor prediction of Fischer model.

- The accuracy and statistical criteria of ANN models of structure (3-12-1) and (4-12-1) are the best of all other examined equations. The performance of ANN models either using in input the combined variable $(\mathrm{Hu} *, \mathrm{w} / \mathrm{H}$ and $\mathrm{U} / \mathrm{u})$ or variables $\mathrm{H}, \mathrm{w}, \mathrm{U}$ and $\mathrm{u}_{*}$ give very close results.

- The accuracy and the statistical criteria of the proposed empirical equation are lower compared to ANN model predictions.

- The reason of low accuracy may be due to the changes in the geometric variables and the velocity distribution in cross section profile due to the intense hydrodynamic changes in the river during the high and low discharge of floods and dry conditions.

- The use of empirical equations from the literature to solve water pollution problems in natural streams have got the risk of low accuracy in predicting the concentration along the stream and the maximum concentration.

The proposed models, either the empirical equation or the ANN models, are more realistic to describe the mass transport in Axios river. In general, the results of this research prove that the empirical equations from the literature are of less accuracy than that derived with data from the river. In the same manner, the ANN models give results of satisfactory accuracy if they are trained with data sets from the river.

The results of this work can be used to predict the distribution of concentration or the variation of maximum concentration along the river for pollutants that may be released upstream the boundary of the transboundary Axios River and can be used as a tool in the direction of protection of river water quality and the Aegean Sea.

Acknowledgments The authors gratefully acknowledge Direction of Public Works (D.E.K.E.) of Thessaloniki, Greece, for providing the hydrometric data at Axioupolis station of Axios River.

\section{References}

Akratos CS, Papaspyros JNE, Tsichrintzis VA (2008) An artificial neural networks model and design equations for BOD and COD removal prediction in horizontal subsurface flow constructed wetlands. Chem Eng J 143: 96-110

Antonopoulos VZ, Antonopoulos ZV (2009) Estimation of dispersion coefficient in Axios river. Proceedings of the conference of the "Greek Hydrotechnical Association" and the "Greek Committee for Water Resources Management”, Volos, pp. 427-434 (in Greek)

Antonopoulos ZV, Vafeiadis M, Katsifarakis KL, Spachos T (2012) Simulation of a karstic aquifer using artificial neural networks. Int. Conf. of Protection and Restoration of the Environment XI, e-proceedings, Thessaloniki pp. 279-287 
ASCE Task committee on application of artificial neural networks in hydrology (2000) Artificial neural networks in hydrology II: Hydrological applications. J Hydrol Eng 5(2):115-123

Chapra SC (1997) Surface water-quality modeling. McGraw-Hill. Inc, New York, p 864

Deng ZQ, Singh VP, Bengtsson L (2001) Longitudinal dispersion coefficient in straight rivers. J Hydraul Eng ASCE 127:919-927

Diamantopoulou MJ, Georgiou PE, Papamichail DM (2006) A time delay artificial neural network approach for flow routing in a river system. Hydrol Earth Syst Sci Discuss 3:2735-2756

Diamantopoulou MJ, Antonopoulos VZ, Papamichail DM (2007) Cascade correlation artificial neural networks for estimating missing monthly values of water quality parameters in rivers. Water Resour Manag 21:649662

Dogan E, Sengorur B, Koklu R (2009) Modeling biological oxygen demand of the Melen River in Turkey using an artificial neural network technique. J Environ Manag 90(2):1229-1235

Etemad-Shahidi A, Taghipour M (2012) Predicting longitudinal dispersion coefficient in natural streams using M5' model tree. J Hydraul Eng ASCE 138:542-555

EU (2000) Directive of the European Parliament and the European Council for the creation of a framework for measures of the union in the area of water policy. Official Journal, L327, 22/12/2000. P.0001

European Community (EC) (1994) Water quality of surface waters - common procedure for exchange of information. General Direction XI. Environment, nuclear safety and public protection

Fahlman SE (1988) An empirical study of learning speed in back-propagation networks. Technical Report CMUCS-88-162. Carnegie-Mellon University

Fischer HB (1967) The mechanics of dispersion in natural streams. J Hydraul Div ASCE 93:187-216

Fischer HB (1968) Dispersion prediction in natural streams. J Sanit Eng Div ASCE 94(5):927-943

Fischer HB (1975) Simple method for predicting dispersion in streams. Discussion by R.S. Mc Quivey and T.N. Keefer. J Environ Eng Div ASCE 101(3):453-455

Fischer HB, List EJ, Koh RCY, Imberger J, Brooks NH (1979) Mixing in inland and coastal waters. Academic, New York

Garcia LA, Shigidi A (2006) Using neural networks for parameter estimation in ground water. J Hydrol 318:215-231

Kashefipour SM, Falconer RA (2002) Longitudinal dispersion coefficients in natural channels. Water Res 36: $1596-1608$

Kourakos G, Mantoglou A (2009) Pumping optimization of coastal aquifers based on evolutionary algorithms and surrogate modular neural network models. Adv Water Resour 32(4):507-521

Koussis AD, Rodriguez-Mirasol J (1998) Hydraulic estimation of dispersion coefficient for streams. J Hydraul Eng ASCE 124(3):317-320

Liu H (1977) Predicting dispersion coefficient of streams. J Environ Eng Div ASCE 103:59-69

Loukas A, Vasiliades L, Dalezios N (2002) A hydrologic modeling procedure using a watershed model and artificial neural networks. Proc. of Inter. Conf. Water Resources Management in the ERA of Transition. European Water Resources Association, Athens, pp 219-228

Maier HR, Dandy GC (1996) The use of artificial neural networks for the prediction of water quality parameters. Water Resour Res 32(4):1013-1022

Mantoglou A (2003) Estimation of heterogeneous aquifer parameters from piezometric data using ridge functions and neural networks. Stoch Env Res Risk A 17:339-352

Mc Quivey RS, Keefer TN (1974) Simple method for predicting dispersion in streams. J Environ Eng Div ASCE 100:997-1011

Pai PF, Lee FC (2010) A rough set based model in water quality analysis. Water Resour Manag 24:2405-2418

Papadimitrakis I, Orphanos I (2004) Longitudinal dispersion characteristics of rivers and natural streams in Greece. Water Air Soil Pollut 4:289-305

Piotrowski AP, Rowinski PM, Napiorkowski JJ (2012) Comparison of evolutionary computation techniques for noise injected neural network training to estimate longitudinal dispersion coefficients in rivers. Expert Syst Appl 39:1354-1361

Rowinski PM, Piotrowski A, Napiorkowski JJ (2005) Are artificial neural network techniques relevant for the estimation of longitudinal dispersion coefficient in rivers. Hydrol Sci J 50(1):175-187

Rutherford CJ (1994) River mixing. Wiley, Chichester

Sahay RR (2013) Predicting longitudinal dispersion coefficients in sinuous rivers by genetic algorithm. J Hydrol Hydromech 61:214-221

Sahay RR, Dutta S (2009) Prediction of longitudinal dispersion coefficients in natural rivers using genetic algorithm. Hydrol Res 40(6):544-552

Sahin S (2014) An empirical approach for determining longitudinal dispersion coefficients in rivers. Environ Process 1:277-285

Sentil-Kumar AR, Sudheer KP, Jain SK, Agarwal PK (2005) Rainfall-runoff modelling using artificial neural networks: comparison of networks types. Hydrol Process 19:1277-1291 
Seo IW, Cheong TS (1998) Predicting longitudinal dispersion coefficient in natural streams. J Hydraul Eng ASCE 124:25-32

Singh SK, Beck MB (2003) Dispersion coefficient of streams from tracer experiment data. J Environ Eng 129(6): 539-546

Tayfur G, Singh VP (2005) Predicting longitudinal dispersion coefficient in natural streams by artificial neural network. J Hydraul Eng ASCE 131(11):991-1000

Trichakis IC, Nikolos IK, Karatzas GP (2009) Optimal selection of artificial neural network parameters for the prediction of a karstic aquifer's response. Hydrol Process 23(20):2956-2969

Valiskova Y, Sokáč M, Halaj P, Koczka Bara M, Dulovičová R, Schügerl R (2014) Pollutant spreading in a small stream: a case study in Mala Nitra Canal in Slovakia. Environ Process 1:265-276 